\title{
Chapter 16 \\ The Western Australian Indigenous Storybook Spins Special Yarns
}

\author{
Melissa Stoneham, Christina R. Davies, and Ray Christophers
}

\subsection{Introduction}

\subsubsection{Storytelling, Yarning, and Storybooks}

A storybook is a form of literature (Davies et al. 2012) that contains a narrative or collection of narratives. The West Australian Indigenous Storybooks (the Storybooks) contain a collection of autobiographical stories and artwork that showcase the achievements of Aboriginal and Torres Strait Islanders (herein referred to as Aboriginal Australians) and communities across Western Australia (HealthInfoNet 2011). Since colonization in 1788, Aboriginal Australians have experienced dispossession of traditional lands, genocidal policies, devastation of families via the forced removal of children (creating a "stolen generation"), and the

\footnotetext{
M. Stoneham $(\bowtie)$

Public Health Advocacy Institute of Western Australia, School of Public Health, Curtin University, Perth, Australia

School of Public Health, Edith Cowan University, Joondalup, Australia

Menzies School of Health Research, Casuarina, Australia

e-mail:m.stoneham@curtin.edu.au

C. R. Davies

Health Humanities - Division of Health Professions Education, School of Allied Health, The University of Western Australia, Perth, Australia

Public Health Advocacy Institute of WA, Curtin University, Perth, Australia

The West Australian Arts and Health Consortium, Perth, Australia

e-mail: christina.davies@uwa.edu.au

R. Christophers

Nirrumbuk Environmental Health \& Services, Nirrumbuk Aboriginal Corporation,

Broome, Australia

e-mail: rchristophers@ nirrumbuk.org.au
} 
everyday stresses of racism (Bretherton and Mellor 2006; Dudgeon et al. 2010). In spite of such profound historical, cultural, emotional, and traumatic experiences, Aboriginal Australians and their communities have shown great resilience.

For Aboriginal Australians, the arts are an important way of building resilience, collaborating, passing on knowledge, and continuing traditions. This is especially the case for storytelling (Kovach 2009), or "yarning," a commonly accepted term for storytelling in Aboriginal culture. Yarning is a traditional communication tool that involves the sharing of stories and knowledge in a manner that is culturally prescribed, cooperative, and respectful (Walker et al. 2014). Building on this rich oral tradition and guided by an Aboriginal Steering Committee (of which author Ray Christophers is a member), the Storybooks are a strengths-based approach that extends storytelling into a written form. Storytelling is timely, accurate, appropriate, and culturally relevant for Indigenous people and their communities (Dei 2011; Iseke 2013). Traditional storytelling acts as a bridge for social transformation for Indigenous worldviews and shapes ethical, theoretical, methodological, and conceptual frameworks (Datta 2017). In the Australian context, Aboriginal knowledge of the land is embedded in the stories of the "Dreaming," which describe the creation of the world (Barrett 2013). Storytelling is ethically appropriate when engaging in projects with Aboriginal Australians and includes a range of practices that are community-based, collaborative, action-oriented, equitable, and grounded in sustained relationships of trust (Datta 2017; Simpson 2014).

\subsubsection{A Background to Aboriginal Australian Health and Well-Being}

To better understand the contemporary realities of Aboriginal life, a demographic, cultural, and health summary is provided below. As of June 2016, it was estimated that the Aboriginal Australian population was 798,400 people, or 3.3\% of the total Australian population (100,512 people or 3.9\% of the Western Australian population) (Australian Bureau of Statistics 2018). The Aboriginal population (median age 23 years) has a younger age structure than the non-Indigenous population (median age 38 years), with a larger proportion of young people and a smaller proportion of older people (Australian Bureau of Statistics 2018). It is estimated that one-third of Aboriginal Australians live in major cities, compared with three-quarters of the nonIndigenous population (Australian Bureau of Statistics 2018).

Aboriginal Australians are one of the most linguistically and culturally diverse populations in the world. At the time of colonization, there were approximately 260 distinct language groups and 500 dialects (Dudgeon et al. 2010). Aboriginal culture embraces family, the land (i.e., "country"), art, spirit, and "lore" (i.e., cultural beliefs). The relationship to family and country is an important part of Aboriginal life as are birthright, shared language, cultural obligations/responsibilities, and social and spiritual activities. 
Aboriginal Australians have a holistic definition of health that acknowledges connection to culture, land, and spirit. There is little need for Aboriginal Australians to untangle the social determinants of health, as their holistic view of health is inclusive of all factors that impact well-being. The National Aboriginal Health Strategy defines Aboriginal health as not simply the physical well-being of an individual, but instead refers to the social, emotional, and cultural well-being of the whole community in which each individual is able to achieve their full potential, thereby bringing about the total well-being of their community. It is a whole-of-life view that includes the cyclical concept of life-death-life (National Aboriginal Health Strategy Working Party 1989). The Aboriginal Australian definition of health aligns with many of the core values of the Ottawa Charter (World Health Organization 1986), including a holistic view of health, participation, and equity. However, with higher rates of chronic disease and disability, the health status of Aboriginal Australians is much lower than that of non-Indigenous Australians (Sun and Buys 2015). While there are many statistics documenting the differences in health, the most telling is life expectancy. In 2010-2012, the estimated life expectancy at birth for Aboriginal males was 69.1 years and 73.7 years for females - this was approximately 10 years lower than the life expectancy for non-Aboriginal Australians (Australian Institute of Health and Welfare 2014). Overall, Western approaches to treating illness and promoting wellness have had limited success on Aboriginal health, primarily because they fail to take into account cultural issues of identity, kinship, family, community, and connection to country (Sun and Buys 2015). Other values that underpin the Ottawa Charter, such as social justice and empowerment, are captured within Aboriginal core values including Aboriginal self-determination principles, community ownership, and localized decision-making (Houston 2006).

\subsection{The West Australian Indigenous Storybook Project}

The West Australian Storybook was developed as one response to the amount of negative media relating to Aboriginal Australians in mainstream media. Negative media about Aboriginal Australians impacts their self-esteem and health and perpetuates racist stereotypes, prejudice, and discrimination (Balvin and Kashima 2012). Following on from a Public Health Advocacy Institute of Western Australia (PHAIWA) media analysis project that found that $74 \%$ of mainstream news coverage about Aboriginal Australians was negative (Stoneham et al. 2014), the need for a more balanced view of Aboriginal life was recognized. With the guidance of regional Elders and an Aboriginal Steering Committee (which has representation from most of the regions across Western Australia), the WA Indigenous Storybook project was initiated in 2011. Examples of the Storybook covers appear in Fig. 16.1. In the past, research and health projects facilitated by non-Indigenous agencies have often been a source of distress for Indigenous peoples because of the use of inappropriate methods and practices (Cochran et al. 2008). This was recognized in this project, and every effort was made to ensure that the processes occurred in a 

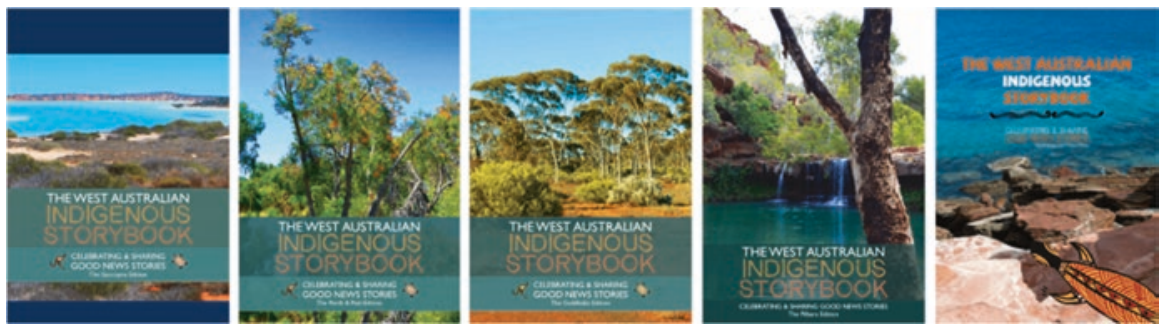

Fig. 16.1 Covers of past issues of the West Australian Indigenous Storybooks

culturally appropriate manner. Through consultation and collaboration, the project team, regional Elders, and the Aboriginal Steering Committee have worked together to:

1. Develop a storytelling process that empowers authors to write about their projects, events, and personal stories using their own words and language.

2. Enable a practice that encourages positive change via the use of positive rather than deficit language (e.g., using terms such as "excellence" and "success" instead of "disadvantage" or "closing the gap").

3. Empower authors to focus on elements that they hold dear to their spirits and hearts. Authors are offered all credit for the knowledge that is shared and have full editorial rights. This enables authors to use storytelling to promote social justice by amplifying their voice as discussed in Chap. 21.

4. Facilitate a practice whereby Aboriginal Elders, authors, and communities lead the storytelling process. For example, each edition of the Storybook focuses on a particular region of Western Australia where cultural similarities and language commonalities occur. At every stage, regional Elders are consulted (especially at the initial stages) to identify which community members should be approached by PHAIWA or which projects/events the community is particularly proud of or pleased with. Storytellers are also recruited via the Aboriginal Steering Committee and partner organizations (e.g., Aboriginal Medical Services, Aboriginal Corporations).

5. Encourage stories about projects and events that are community driven, developed, and implemented (Fletcher 2007), thereby recognizing the power Aboriginal methods can bring to a project/event and the benefits these stories can provide to other Aboriginal communities facing similar issues.

6. Enable stories that represent equity and discuss what is fair and just through an Aboriginal lens.

Through storytelling, authors reflect on and explain the rationale, implementation, outcomes, and potential future of their specific community project/event. The stories address a broad array of social and cultural determinants of health and embrace the holistic culture of Aboriginal Australians. Past story subject examples include art, mental health, preventive health, education, environmental sustainability, and sports programs/events. Stories also focus on individuals who are community 
leaders or emerging leaders who have achieved positive outcomes for their community.

To facilitate the storytelling process, a template was developed as a tool to provide guidance to potential authors. Figure 16.2 provides an example of how the stories look within each Storybook. The storytelling template was developed and pilot-tested with advice and guidance from the Aboriginal Steering Committee. The template is available electronically, in written form, or can be provided to the project team verbally. First, the template asks for information about the storyteller and their project/event/narrative (e.g., their name, project/event information, cultural background, organization, program partners, and the key people involved). Contact details for the authors are always provided to enable a reader to contact them directly. Second, the heading "Once upon a time" is presented to the storyteller and encourages the storytellers to reflect on the background or rationale for their story. This heading sets the context for the story and provides important details such as initiating factors, cultural considerations, or a brief history prior to the program/ event. Third, the storyteller is presented with the heading "And then one day." This part of the template encourages the storyteller to focus on the issues the story is targeting. Fourth, the story heading "And because of that" provides the storyteller an opportunity to write about the outcomes of the project/event that has occurred. In this section, some stories also include a discussion of problems, limitations, barriers, or setbacks that arose during the project implementation under a sub-heading titled "Unfortunately." Lastly, the storyteller is presented with the heading "And since that day," where the storyteller outlines the outputs, impacts, and outcomes they have achieved. Although this template could be considered a "Western" storytelling framework, the pilot testing, approval by the Aboriginal Steering Committee, evaluation, and subsequent publication of ten Storybooks over a period of 6 years demonstrates that this is an acceptable method and a holistic way to ensure that each story is written about in full and has an introduction, a middle, and an end.

Once complete, each Storybook has a regional launch where the storyteller is formally acknowledged and presented with a copy of the Storybook. Politicians, local leaders, and the media regularly attend these launches, which provide storytellers the opportunity to speak about their projects. The launch also allows PHAIWA to show its appreciation to the storytellers for their engagement and time in being involved in the storytelling process. The Storybook has its own website (https:// www.phaiwa.org.au/indigenous-storybook/) and Facebook account (www.facebook.com/PHAIWA) and is tweeted from the PHAIWA account (@PHAIWA). The project has been funded since its inception by The Western Australian Health Promotion Foundation (Healthway). 


\section{ROEBOURNE ART GROUP}
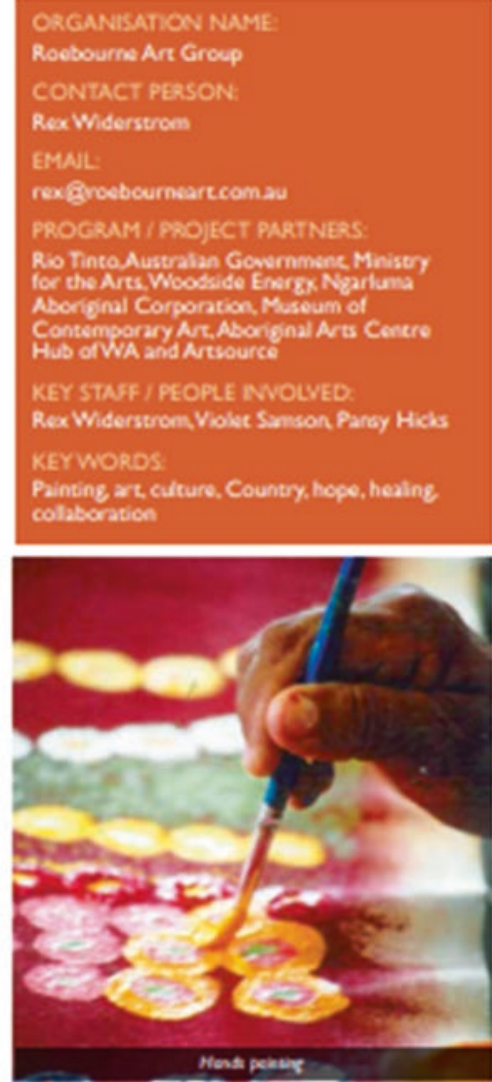

Once upon a time...

Roebourne Avt Groep (RAG) formed in 2007. At the time, bod artsas were panting indeperdenty in undl clusters but al joined topether under ore root which everturly became the Roeboume Art Group h june 2017 we had the opporturity to move irte the Rostourne Vutors Ceroere which is our currere premies This is the oid Rosboume gad and the buling which was bult in 1886, has a was history
About the Storyteller...

Rex Wrderstarm as the CEO \&a Rocbourne Are Group

About the Roebourne Art Group...

Rosbeurne Are Grous a beaed in the Pibura Regon of Wh What a mambership of around 70 artacs of Abor gnal and Torres Senit thander backgrounda, RAG is the regicn's cely ectalve art goop. in contmon wich Aborional areses from cecher parts of Austrilis, ocr artists panc their stories from "Swhen the world was solk" belore creation, to contemporacy places reflocting the realicy of lifle today in che of the country tiscuphest, most remote locations. Rosbourne Art Group represants Aboridimal

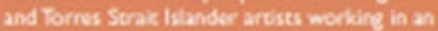
area bat is heme to many dillorent bngage 20ups.

which our peaple had to come to terms with Some cour artists were a Imle be wary when we were first offered this space, wo I abed our Bders how they fet dbout at. One of our Bdern. Aunty Voles wid. "Wilt if there are ghois up pere then theyll hoep people away fom stealing our art' So we accepted Dout and 2 became our now home

When we firg moved in there were a fow iseuss to won ous before we could start functoring properly is an art space. As the bulding is hisoricaly listed, $z$ Nud certan resorictions We werent alowed to pef in fixeurss of ary kind in the imterior. That rived ouf picture hooks on the wals or in the beims in the ceing Athough we were gratefl to be provided with the space, withoat beng atle to for our art work to the walk or hang a from the celing we were faced whth a diemma

Howeves this provided an opporturity for a communty cal to arms We pre the word out to local bubrestes and the Construction Forestry Minge ind Energy thicn (CFMEU) came forwerd and oflored to help They enkted the help of severd. firms that were workirg on wailas projects in the Pibza who colectively ext on bourd - Brockfield Mutiplev Cooper and Oxley pint Versure and

Fig. 16.2 Storybook example - "Roebourne Art Group" 


\subsection{Evaluation}

As of 2019, ten Storybooks have been published. Two editions of the Storybook have been produced every 18 months and typically contain 13 stories. The Storybooks are produced in full color, with numerous photographs and "callout" quotes. Although available via the Storybook website (https://www.phaiwa.org.au/ indigenous-storybook/), the Storybooks are also produced in hard copy, as the look and feel of the Storybook has been a critical factor of the project's success. In 2016, an extensive process and impact evaluation of the Storybook took place. The evaluation found that between 2011 and 2016:

- 141 authors had contributed to 93 stories,

- 1800 hard copies of the Storybook had been distributed to over 460 media, arts, sport, government, and non-government organizations,

- 10,255 electronic downloads occurred from the PHAIWA website,

- 7 Storybook launches took place, and 345 people attended a Storybook launch.

- These Storybooks should definitely continue because they are about community people and sharing stories. People love having hard copies to share and show with family and friends. (Survey respondent, author, female, Aboriginal, health professional, 2018)

- It is a great resource for the projects highlighted in the book but also for others that read the book to see the great and varied projects that are happening around the state. (Survey respondent, author, female, Aboriginal, media, 2018)

Storytellers were also invited to complete an evaluation survey (via paper or telephone). Forty storytellers responded to the survey. Overall, it was found that the majority of respondents were happy or extremely happy with the Storybook template $(95 \%)$, the presentation of the Storybook (98\%), the look and feel of the Storybook (98\%), the photos (98\%), and the Storybook launch $(98 \%)$. Storytellers indicated that the launch was important and was a positive opportunity for people to come together, meet new people, learn about other projects in the community, and network with key stakeholders.

A great tool to inspire change and innovation in communities. Well done. (Survey respondent, author mentor, female, Aboriginal, health professional, 2018)

People are so impressed with the edition! Each one [story] is such an achievement. This gave us an opportunity to blow the trumpet, building morale and hopefully triggering other good things in the community. What a beautiful occasion the launch was ... and I'm loving the book. The article is a retrospective view that is wonderful to have in our 10th anniversary year. I hope the will is there to allow the Storybook to continue. We felt nurtured by the experience. That's most appreciated! Thanks so much - the concept is a real winner! (Survey respondent, author, female, Aboriginal, artist, 2019)

I really appreciated the opportunity. It was a really good experience from first contact to the launch! (Survey respondent, launch attendee, female, Aboriginal, health professional, 2019) 
Overall, $78 \%$ of respondents advised that they had forwarded either a hard or an electronic copy of their Storybook to another person, but indicated that the distribution of the book needed to be more extensive so as to encourage community-based innovation, to more widely promote the positive Aboriginal projects/events that are occurring, and to counteract ubiquitous negative media pertaining to Aboriginal Australians.

I thought the launch was great, however we need to be able to influence 'the other' mainstream services, media, and community to understand Aboriginal people and ways of working with the Aboriginal community. (Survey respondent, female, launch attendee, Aboriginal, Aboriginal Foundation, 2018)

Common feedback from the storytellers was that they felt extremely proud to see their stories in print and thought the Storybooks were a valuable record of their work. Storytellers wanted to share the Storybooks with clients, their community, management, and others more broadly (i.e., other communities and government and non-government organizations), therefore making it a valuable bridge for social transformation between and amongst sectors.

I loved seeing my story in print, you did a great job of representing who I am and this is something I will always be proud of, show my children, and keep forever. Thank you. (Survey respondent, author, male, Aboriginal, consultant, 2018)

Brilliant! Thank you. Everyone we have shared the book with has loved it and appreciated the opportunity to hear about what others are doing. It is a book that gets read (not one for the shelf!). There are so many wonderful projects and ideas out there, we don't always get to hear about the good news- especially when it's community projects operating on little budgets doing great work right there on the ground. (Survey respondent, author, female, Aboriginal, Aboriginal Corporation, 2019)

Some storytellers used the Storybooks to generate new interest in their projects or as a tool to successfully secure more funding. Storytellers advised that the Storybooks enabled the replication of successful projects or the creation of new partnerships, and that the sharing of barriers or project problems enabled the development, better design, and increased cost effectiveness of new projects within the community. Respondents also indicated that it was beneficial to have local leaders acknowledged and celebrated via personal narratives, as this increased respect and community cohesiveness. Overall, the Storybooks were found to have an immensely positive impact on Aboriginal people and communities by enhancing connections, communication, self-esteem, positive social identity, and knowledge. The vast majority of respondents felt that the Storybooks should continue to be published (98\% agree, $2 \%$ unsure).

These articles assist with the stigma attached in society, changing views and acknowledging achievements. (Survey respondent, partner, female, Aboriginal, health professional, 2018)

There are lots of untold stories in the community so keep this going! (Survey respondent, launch attendee, female, Aboriginal, teacher, 2019) 


\subsection{Key Learnings, Outcomes, and Benefits}

Through the arts practice of storytelling — which seeks human and social well-being by developing human capacities; personal growth; and social relationships of equality, freedom, and mutual relationship — people are able to flourish (Payne 2011). As suggested via the evaluation feedback, the arts/storytelling process has the power to inspire creativity, invention, self-critique, and self-transcendence (Bauman 1999), and to act as a vehicle to achieve well-being through opportunities for engagement, artistic expression, self-awareness, and skill development (Sen 1992). The storytelling process and the publishing of a high-quality artifact that the storyteller is proud to be associated with (i.e., the Storybook) supports the capacity for authors and their communities to aspire for the future and (via the provision of contact details in each story) to connect with Aboriginal and non-Indigenous members of the community, especially those interested in creating or replicating similar projects/events (Appadurai 2004).

One of the most important things the project team has learned from the Storybooks is that when people are provided with a method of communication that is nonthreatening and culturally appropriate, they are comfortable, relaxed, and happy to share their experiences. In addition, when Aboriginal Australians are supported to share their stories, innovation can flourish. We have also learned that the best solutions to remedy local issues come from the community themselves; PHAIWA's role is mostly administrative, with the Aboriginal Steering Committee, Community Elders, and storytellers acting as the innovators and leaders in this project. The ideas for the stories come from the storytellers themselves, and the innovative projects are already happening in communities across Western Australia. The Storybooks provide a forum and opportunity to share these ideas/projects/events that may otherwise go untold or unrecognized. This is why the Storybooks are so important-for now and into the future. As suggested via evaluation feedback, the Storybooks not only provide an outlet for people's voices, they also contribute to a sense of pride, ownership, and mental and social well-being. The Storybooks provide authors with the opportunity to tell their stories in their own words and in a manner that is compatible with the traditional yarning process. The Storybooks are also a creative tool to tap into the valuable yet commonly overlooked social capital resource that exists within many Aboriginal communities and empowers Aboriginal storytellers to tell and write their stories for wider dissemination. This project recognizes that communication needs to be about more than transmitting information and assuming it will be understood and acted upon. This project involves the transformation of health knowledge into key messages that can be readily understood, accepted, and put into action by other Aboriginal communities or practitioners.

As with most projects, a number of challenges were experienced. Some related to literacy levels of some storytellers, as English was often their third or fourth language. This was easily remedied via the help of a translator; however, the translation process often extended the project timeframe. Another challenge that often extended the timeframe of producing an individual Storybook was the length of time needed 
for storytellers to read, edit, and approve individual stories. Patience was a muchneeded attribute in this project. In rare cases, a story was retracted by a storyteller prior to publication due to a change in circumstance in their community or a death within the community.

Overall, the West Australian Indigenous Storybook project bridges a number of public health practice gaps. First, it bridges a gap between geographically dispersed and often remote communities and encourages them to contemplate whether they could replicate the positive projects or activities in the Storybooks. Communities therefore have the opportunity to learn from each other, communicate, offer support, and share knowledge. Second, the Storybook project builds understanding of Aboriginal people, communities, and culture by the non-Indigenous population, who often do not actually know or interact with Aboriginal people or who are only exposed to Aboriginal culture via the media. Third, it provides storytellers, their communities, and their organizations with opportunities to strengthen existingand create new - partnerships. And fourth, the Storybooks are an advocacy tool that can be used for many purposes, including promoting Aboriginal projects and applying for or extending program funding. For PHAIWA, the Storybooks have resulted in many positive outcomes, especially stronger links with Aboriginal people and their communities.

\subsection{Conclusion}

The West Australian Indigenous Storybook project is a tool to promote positive narrative. It empowers authors to write about projects, events, and personal stories that they hold dear to their spirits and hearts, using their own words and language. The process is author- and community-led and blends and creates a bridge between Aboriginal and Western storytelling methodologies while taking into account the values, practices, and beliefs of Aboriginal peoples in a way that is respectful and inclusive. The Storybook project values the broad and disparate expertise and understanding that exists in communities and strives to advance and disseminate activities that are of mutual benefit to both Aboriginal and non-Aboriginal people in an effort to enhance the wellness of Aboriginal Australians and diminish negative stereotypes. The Storybooks create a strong and relational means of arts engagement with storytellers, their communities, and the wider non-Indigenous community and provide an ever-expanding, self-sustaining living archive of innovative, successful, constructive, and readily available knowledge, information, and expertise.

Acknowledgement The authors would like to thank Ms. Sunni Wilson for her assistance in providing some of the data for this Chapter. 


\section{References}

Appadurai, A. (2004). The capacity to aspire: Culture and the terms of recognition. In V. Rao \& V. Walton (Eds.), Culture and public action (pp. 59-84). Palo Alto: Stanford University Press.

Australian Bureau of Statistics. (2018). Aboriginal and Torres Strait Islander peoples. Retrieved from http://www.abs.gov.au/Aboriginal-and-Torres-Strait-Islander-Peoples

Australian Institute of Health and Welfare. (2014). Mortality and life expectancy of Indigenous Australians: 2008 to 2012. Retrieved from https://www.aihw.gov.au/getmedia/b0a6bd57-0ecb45c6-9830-cf0c0c9ef059/16953.pdf.aspx ?inline=true

Balvin, N., \& Kashima, Y. (2012). Hidden obstacles to reconciliation in Australia: The persistence of stereotypes. In D. Bretherton \& N. Balvin (Eds.), Peace psychology in Australia. New York: Springer Science and Business Media.

Barrett, S. (2013). "This land is me": Indigenous Australian story-telling and ecological knowledge. Retrieved from https://journals.openedition.org/elohi/592

Bauman, Z. (1999). Culture as praxis. London: Sage Publications.

Bretherton, D., \& Mellor, D. (2006). Reconciliation between Aboriginal and other Australians: the "stolen generations". Journal of Social Issues, 62(1), 81-98.

Cochran, P., Marshall, C., Garcia-Downing, C., Kendall, E., Cook, D., McCubbin, L., et al. (2008). Indigenous ways of knowing: Implications for participatory research and community. American Journal of Public Health, 98(1), 22-27.

Datta, R. (2017). Traditional storytelling: An effective indigenous research methodology and its implications for environmental research. AlterNative: An International Journal of Indigenous Peoples. Retrieved from http://journals.sagepub.com/doi/10.1177/1177180117741351

Davies, C., Rosenberg, M., Knuiman, M., Ferguson, R., Pikora, T., \& Slatter, N. (2012). Defining arts engagement for population-based health research: Art forms, activities and level of engagement. Arts \& Health, 4(3), 203-216.

Dei, G. (2011). Indigenous philosophies and critical education: A reader. New York: Peter Lang.

Dudgeon, P., Wright, M., Paradies, Y., Garvey, D., \& Walker, I. (2010). The social, cultural and historical context of Aboriginal and Torres Strait islander Australians. In Working together: Aboriginal and Torres Strait islander mental health and wellbeing principles and practice (pp. 25-42). Canberra: Australian Institute of Health and Welfare.

Fletcher, S. (2007). Communities working for health and wellbeing: Success stories from the aboriginal community controlled health sector in Victoria. Fitzroy: Victorian Aboriginal Community Controlled Health Organisation and Cooperative Research Centre for Aboriginal Health.

HealthInfoNet. (2011). The West Australian Indigenous storybook: celebrating and sharing good news stories - the Kimberley and Pilbara edition. Retrieved from http://healthbulletin.org.au/ articles/the-west-australian-indigenous-storybook-celebrating-and-sharing-good-news-stories-the-kimberley-and-pilbara-edition/

Houston, S. (2006). Equity, by what measure? Health Promotion Journal of Australia, 17(3), 2006-2009.

Iseke, J. (2013). Indigenous storytelling as research. Indigenous Storytelling as Research, 6(4), 559-577.

Kovach, M. (2009). Indigenous methodologies: Characteristics, conversations, and contexts. Toronto: University of Toronto Press.

National Aboriginal Health Strategy Working Party (1989). A national Aboriginal health strategy. Canberra: National Aboriginal Health Strategy Working Party.

Payne, M. (2011). Humanistic social work: Core principles in practice. Chicago: Lyceum Books. Sen, A. (1992). Inequality reexamined. New York: Russell Sage Foundation Clarendon Press.

Simpson, A. (2014). Mohawk interruptus: Political life across the borders of settler states. Durham: Duke University Press.

Stoneham, M. J., Goodman, J., \& Daube, M. (2014). The portrayal of indigenous health in selected Australian media. The International Indigenous Policy Journal, 5(1), 1-13. 
Sun, J., \& Buys, N. (2015). Addressing the health needs of indigenous Australians through creative engagement: A case study. In S. Clift \& P. Camic (Eds.), Oxford textbook of creative arts, health and wellbeing. Oxford: Oxford University Press.

Walker, M., Fredericks, B., Mills, K., \& Anderson, D. (2014). "Yarning" as a method for community-based health research with indigenous women: The indigenous women's wellness research program. Health Care for Women International, 35(10), 1216-1226.

World Health Organization. (1986, November 21). The Ottawa Charter for health promotion: First international conference on health promotion, Ottawa. Retrieved from https://www.who.int/ healthpromotion/conferences/previous/ottawa/en/

Open Access This chapter is licensed under the terms of the Creative Commons AttributionNonCommercial-NoDerivatives 4.0 International License (http://creativecommons.org/licenses/ by-nc-nd/4.0/), which permits any noncommercial use, sharing, distribution and reproduction in any medium or format, as long as you give appropriate credit to the original author(s) and the source, provide a link to the Creative Commons license and indicate if you modified the licensed material. You do not have permission under this license to share adapted material derived from this chapter or parts of it.

The images or other third party material in this chapter are included in the chapter's Creative Commons license, unless indicated otherwise in a credit line to the material. If material is not included in the chapter's Creative Commons license and your intended use is not permitted by statutory regulation or exceeds the permitted use, you will need to obtain permission directly from the copyright holder.

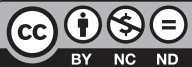

